\title{
Ergonomics-related risk identification and pain analysis for farmers involved in rice field preparation
}

\author{
Manida Swangnetr ${ }^{\mathrm{a}, \mathrm{e}, *}$, David B. Kaber ${ }^{\mathrm{b}}$, Rungthip Puntumetakul ${ }^{\mathrm{c}, \mathrm{e}, \mathrm{f}}$ and Michael T. Gross ${ }^{\mathrm{d}}$ \\ ${ }^{a}$ Department of Production Technology, Faculty of Technology, Khon Kaen University, Khon Kaen, Thailand \\ ${ }^{\mathrm{b}}$ Edward P. Fitts Department of Industrial and Systems Engineering, North Carolina State University, Raleigh, NC, \\ USA \\ ${ }^{\mathrm{c}}$ Division of Physical Therapy, Faculty of Associated Medical Sciences, Khon Kaen University, Khon Kaen, \\ Thailand \\ ${ }^{\mathrm{d}}$ Division of Physical Therapy, Department of Allied Health Sciences, University of North Carolina at Chapel Hill, \\ NC, USA \\ ${ }^{\mathrm{e}}$ Back Neck and Other Joint Pain Research Group, Khon Kaen University, Khon Kaen, Thailand \\ ${ }_{\mathrm{f}}^{\mathrm{f}}$ Improvement of Physical Performance and Quality of Life Research Group, Khon Kaen University, Khon Kaen, \\ Thailand
}

Received 23 December 2012

Accepted 7 August 2013

\begin{abstract}
.
BACKGROUND: A previous ergonomic screening of rice field preparation revealed farmer exposure to high risks of musculoskeletal disorders at the shoulders, hands, wrists and back. The screening method was not applied to muddy soil farming in which analysts could not observe farmer legs and feet. This study analyzed farmer pain in all stages of field preparation.

OBJECTIVE: To examine the relationship of farmer experience and demographics to perceptions of pain and to identify body areas exposed to ergonomics risks, unknown to farmers. Results were expected to support interventions and guidelines for famers on physical behaviors towards minimizing risk of injury as well as validation of the screening approach.

METHODS: Comparison of analyst screening results and farmer pain ratings using self-ratings and interviews.

RESULTS: Farmer experience and age were significantly correlated with occurrence of pain and cramping. Less experienced farmers reported less pain in high-risk body parts (e.g., neck and lower back). More experienced farmers reported more pain in the legs, as compared with analyst risk ratings.

CONCLUSIONS: Results demonstrated less experienced farmers to be unaware of critical areas of exposure to ergonomics risks. Correlation of farmer ratings of pain with analyst risk assessments support validity of the screening method for hazard identification and control.
\end{abstract}

Keywords: Rice cultivation, job screening, farmer demographics, pain ratings

*Corresponding author: Manida Swangnetr, Department of Production Technology, Faculty of Technology, Khon Kaen University, Khon Kaen, Thailand. Tel.: +66 4320 2403; Fax: +66 4334 3182; E-mail: manida@kku.ac.th.

\section{Introduction}

Rice farming is one of the most important agricultural industries in the world. Although China is the largest producer of rice, Thailand is the largest rice exporting country, particularly for Jasmine rice. The de- 
mand for Jasmine rice in Europe and the U.S. has increased recently [1-3]. As a result, Thailand has significantly increased rice production from 25.8 million tons in 2000 to 32 million tons in 2009 [4], which is attributed to an increase in farming activities in the northeastern region of the country [4]. Unfortunately, recent major flooding caused severe damage to crops estimated to amount of 3.5 to 4 million tons in some parts of the northeast and central regions [5]. Due to current Jasmine prices in the global market, it is forecasted that Thailand will dramatically increase rice production in 2012 to compensate for flood losses [5]. With this increase in productivity, rice farmer health and safety have become a major concern for the Thai government and massive farmer cooperatives throughout Thailand in order to sustain a sufficient work force.

Prior research has shown that musculoskeletal disorders (MSDs) are the most common of all occupational non-fatal injuries and illness for farm workers $[6,7]$. Many processes are involved in rice cultivation, including field preparation, seeding, planting, nursing and fertilization, and harvesting. Some common MSDs in rice cultivation include low back pain and hand and wrist disorders [6-8]. The field preparation process poses high energy-consumption demands on rice farmers [9]. This task is performed in multiple stages, including plowing, harrowing, and leveling. These activities involve the use of heavy machinery (e.g., power tillers) and awkward postures, as well as highly repetitive movements. These work factors have been associated with MSDs [10]. In the northeastern region of Thailand, initial field preparation is typically performed on dry and friable soil and involves tilling the soil and removing weeds. The rice fields are then flooded with water and left for a week before performing the rest of the process. Each stage also requires farmers to make several laps around a field with a plow (see Fig. 1) over an extended period of time. This process typically involves the use of vibrating machinery with bare hands and feet, which can also lead to an ischemic effect in body parts causing fatigue. In general, such body loading and vibration exposure represent a major occupational injury risks for workers [11].

Previously, task analysis and systematic screening of the initial field preparation on dry soil were performed to identify ergonomics-related risk factors [12]. Four expert ergonomics analysts made direct observation of farmer work, reviewed videos of task performance, and applied a structured risk rating methodology. The methodology was based on the Hand Activity Level (HAL) measure [13] and Rapid Upper
Limb Assessment (RULA) methodology [14] and involved assessment of the potential risk of injury for all body parts due to posture, force, or repetition. Results revealed farmer exposure to repetitive motion, high forces, and extreme postures at the shoulders, hands, wrists, and legs when farmers performed straight plowing and cleared debris. Across all subtasks, as part of the initial field preparation, the right shoulder, hand, wrist, and back were body parts at greater risk for injury. However, the ergonomics screening analysis was not extended beyond the dry soil plowing stage. The screening method could not be applied to the harrowing and leveling stages during which farmers' calves and feet are immersed in mud, preventing analyst observation.

Some studies have found a relationship between ergonomics risk evaluation and subjective body part ratings (e.g. [15]) and, therefore, these methodologies might be used concurrently. On this basis, the present study extended the prior job screening research by conducting a pain analysis with farmers using self-ratings and interviews for all stages of rice field preparation. The study also made comparisons between the prior results of the ergonomics job screening by expert analysts with the subjective responses from farmers. This analysis was intended to: (a) identify critical areas of body exposure to hazards not known by farmers, particularly farmers with less experience; (b) provide data for further validation for use of the job screening approach by analysts for identifying ergonomic risks; and (c) to provide a basis for recommending methods (ergonomic interventions) that might reduce farmer MSDs.

Based on the field observations as part of the job screening study [12], expert rice farmers also appeared to follow highly specialized patterns of movement behavior and postural control that led to smoother muscle contractions and less exertion than inexperienced farmers. Related to this, studies on sport and occupational work indicate that experts develop efficient and safer movement strategies [16-18] and generate more muscle strength [18] with less fatigue [19,20], as compared with novices. Years of task experience has also been widely used to indicate levels of expertise (e.g. [17, $18,20])$. Some studies have also identified that anthropometric characteristics (e.g., weight, standing height, body mass index (BMI) ) may be determinants of expert task performance [21]. Beyond this, several studies have shown that age is a predictor of muscle force output variability for older adults [22,23].

Consequently, the purpose of the present study was to examine the relationship of farmer experience and 


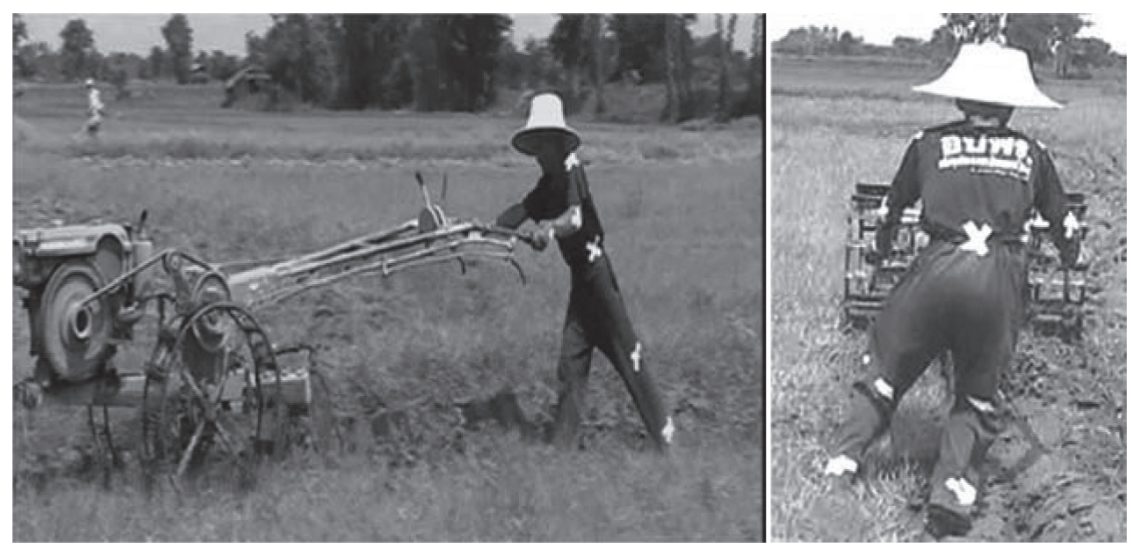

Fig. 1. Side and back view of farmer performing initial rice field preparation.

demographics to perceptions of pain. We also sought to identify critical areas of body exposure to hazards unknown to farmers and whether farmer expertise (experienced vs. novice) was predictive of sensitivity to potential risks of injury among body parts. More specifically, pain ratings for groups of farmers were compared with the expert analyst ergonomic risk ratings. Such results may be useful for developing ergonomic interventions as well as training guidelines for farmers on physical behaviors to minimize risk of injury. Comparison of analyst risk and farmer pain ratings was also expected to provide a basis for validation of the screening method.

\section{Methodology}

\subsection{Participants}

Twelve farmers with different levels of experience in rice field preparation were recruited from local farms in Khon Kaen province, Thailand. Only male participants were used in this study, as they represent the majority of Thai farmers performing field preparation activities. All participants had experience using power tillers. Participants were excluded if they were currently experiencing chronic pain in any body part within 2 weeks prior to testing, such as gouty arthritis, rheumatoid arthritis or ankylosing spondylitis, and/or had an accident causing a fracture of any bone or dislocation of a joint.

\subsection{Apparatus and task}

Participants were asked to rate body pain they experienced during field preparation activities. Each partic-
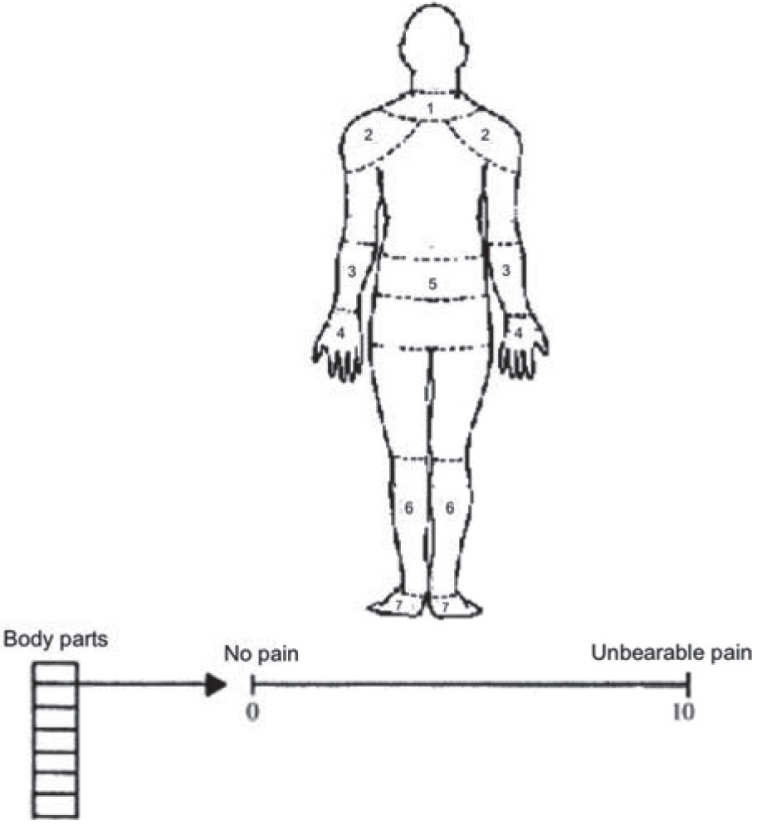

Fig. 2. Body map and rating scale for body part discomfort questionnaire.

ipant completed one set of pain ratings. For this purpose, we used a modified version of the Standardized Nordic Questionnaire (SNQ; 24) for body part discomfort rating. The form was translated into Thai and was validated for comprehension and sensitivity in a previous study [25]. In the questionnaire, a posterior view of the body was presented with spaces for rating pain levels for each body region, including: neck, shoulders, arms and hands, lower back, legs, and feet (see Fig. 2). Ratings were based on a scale from 0 to 10 points, where 0 represented no pain and 10 was unbearable pain. 
Table 1

List of questions used in farmer interviews

\begin{tabular}{cl}
\hline Question \# & Question \\
\hline 1 & Where, specifically are you having pain [in your body]? Please identify the specific body part. \\
2 & $\begin{array}{l}\text { What is the magnitude of this pain, when it is at its worst, on a scale from 0-10. Please consider } 0 \text { to represent no pain and } 10 \\
\text { to be unbearable pain? }\end{array}$ \\
3 & $\begin{array}{l}\text { How long do you work before the onset of this body pain (e.g., } 30 \mathrm{~min} ., 1 \mathrm{hr} ., 3-4 \mathrm{hrs} .,>4 \mathrm{hrs} .) \\
4\end{array}$ \\
5 & $\begin{array}{l}\text { What action do you take when this pain is at its worst? } \\
\text { furrow, pushing-up off the ground while your foot is in the furrow, bearing weight directly over your foot while it is in the } \\
\text { furrow, pushing-off while walking over level ground, bearing weight directly over your foot while walking over level ground, } \\
\text { etc.). }\end{array}$ \\
& Do you experience any leg and/or foot cramping as a result of the field preparation activity?
\end{tabular}

Table 2

Demographic data on participants

\begin{tabular}{lrr}
\hline Demographic & Mean & \multicolumn{1}{c}{ SD } \\
\hline Age (years) & 37.25 & 13.53 \\
Height (centimeter) & 162.83 & 5.54 \\
Weight $(\mathrm{kg})$ & 58.17 & 6.28 \\
BMI $\left(\mathrm{kg} / \mathrm{m}^{2}\right)$ & 21.96 & 2.32 \\
Experience (years) & 14.33 & 11.35 \\
\hline
\end{tabular}

Interviews were subsequently conducted with the farmers regarding: (a) working duration before the occurrence of pain; (b) methods used by the farmer in the field in an attempt to reduce pain when sensations were most intense; (c) locations of body discomfort for each phase of the gait cycle, particularly when walking in a furrow and over level ground, as part of the field preparation process; and (d) the occurrence of leg or foot cramping during, or as a result of, the field preparation activity. Farmers tended to report cramping voluntarily while rating leg and foot pain, but the investigators asked them about cramping directly to ensure a complete response record. Registered physical therapists administered all questionnaires and conducted all interviews. Table 1 presents the specific questions we posed to the farmers during interviews. Responses were solicited to Questions 1-5 for each anatomical location of pain. For farmer pain characterizations during the interviews, we presented a $10 \mathrm{~cm}$ visual analog scale with anchors of "no pain" and "unbearable pain" with tick marks at each centimeter, similar to the scale used in the SNQ. They placed a vertical mark on the scale to reflect their level of pain at any anatomical location for the interviewer. Pain was measured on this scale to the nearest $\mathrm{cm}$; that is, pain ratings were discretized to values of 0 to 10 corresponding with each $\mathrm{cm}$ on the VAS. A binary response was recorded for Question 6.

It is important to note that the farmer self-ratings of pain and interviews were conducted at the end of a workday during the latter part of the field preparation season as part of rice cultivation in the Khon Kaen re- gion. Therefore, all farmer ratings and responses to interview questions were considered to represent farmer pain levels primarily due to performing this stage of the cultivation process.

\subsection{Hypotheses}

We hypothesized (H1) that farmers' pain ratings would be consistent with the ergonomic analysts' assessments of risk of body part injury based on the job screening. As previously mentioned, the job screening method applied in our previous study [12] was based on existing industrial ergonomics screening tools. The specific method we used was developed by the Ergonomics Center of North Carolina and has been successfully applied in prior studies [26,27] for identifying ergonomics-related risk factors in manual work and as a basis for specifying effective ergonomic interventions. Regarding the SNQ, its widespread use and practical quality was cited in an examination of musculoskeletal symptom surveys by Baron et al. [28]. Therefore, these two methods were expected to convey similar results on body part risk and discomfort and serve as further validation of the job screening results based on actual farmer musculoskeletal symptoms. In the event that risk assessments deviated from pain ratings, it is possible there were ergonomics-related risk exposures unknown to the investigators and/or farmers. In addition, subjective discomfort might be influenced by other factors, such as worker experience, expectations, attitudes, physiological reactions and mental stress [29]. Consequently, some aspects of discomfort may be unrelated to the potential risks associated with jobs.

We also hypothesized (H2) that farmer demographics would be correlated with pain ratings. Previous studies [17-19] have shown that workers with greater number of years on task (indicative of higher levels of expertise) report reduced pain ratings. We expected the 
Table 3

Descriptive statistics of rating scores for each body part from expert analysts and farmers (numbers in parentheses are standard deviations)

\begin{tabular}{lcc}
\hline Body parts & Analyst ratings & Farmer ratings \\
\hline Neck & $1.70(0.21)$ & $1.33(2.90)$ \\
Shoulder & $4.89(0.12)$ & $3.42(3.15)$ \\
Forearm & $5.13(0.33)$ & $2.92(2.15)$ \\
Hand & $5.82(0.16)$ & $2.92(2.15)$ \\
Lower back & $4.68(0.18)$ & $1.25(2.26)$ \\
Leg & $4.44(0.42)$ & $5.50(4.76)$ \\
\hline
\end{tabular}

same among the rice farmer population (H2.1) sampled for the present study, assuming the more experienced farmers used more efficient motion patterns and generating more muscle force output with less fatigue [1620]. We also hypothesized (H2.2) that older farmers would have greater muscular discomfort as a result of lower physiological capacity and quicker onset of fatigue and discomfort [22,23,30]. Finally, we expected that smaller farmers (in terms of height and weight) might produce lower pain ratings $(\mathrm{H} 2.3)$ due to lower loads at the joints (from biomechanical perspective; 30). In addition, from the sport science literature [21], task experts have been found to be significantly smaller in height and to have lower body mass than novices.

\section{Data analysis and results}

\subsection{Descriptive statistics}

The descriptive statistics for farmer demographic characteristics are presented in Table 2. On average, the farmers were close to middle-age with substantial field experience (approximately 15 yrs.) and had relatively low BMIs. The descriptive statistics of rating scores for each body part from expert analysts and farmers are presented in Table 3. The ergonomic job screening was conducted on a subset of farmers, who participated in the present study. The screening was based on the most extreme postures, force and repetition in subtask performance.

\subsection{Comparison of expert analyst screening results and farmer pain ratings}

The analysts' risk ratings for each body part were averaged across all subtasks in the plowing process. This yielded a single risk score for each part per analyst with values ranging from 0 , or "no risk", to 10 , or "maximum risk". Since there were only four analysts in our prior study and 12 farmers in the present inves-
Table 4

Welch's test results on rating scores between analysts and farmers for each body part

\begin{tabular}{lll}
\hline Body parts & \multicolumn{2}{c}{ Rating scores } \\
\hline Neck & $\mathrm{F}(1,11.348)=0.1930$ & $p=0.6687$ \\
Shoulder & $\mathrm{F}(1,11.09)=2.6055$ & $p=0.1346$ \\
Forearm & $\mathrm{F}(1,12.395)=11.9064$ & $p=\mathbf{0 . 0 0 4 6}^{*}$ \\
Hand & $\mathrm{F}(1,11.369)=21.4168$ & $p=\mathbf{0 . 0 0 0 7}^{*}$ \\
Lower back & $\mathrm{F}(1,11.426)=27.0459$ & $p=\mathbf{0 . 0 0 0 3}^{*}$ \\
Leg & $\mathrm{F}(1,11.478)=0.4771$ & $p=0.5035$ \\
\hline
\end{tabular}

Note: $*$ - significant at alpha $=0.05$ level.

tigation, we used a parametric test for unequal sample sizes and possibly unequal variances to compare risk and pain ratings. Welch's t-test was used to compare the ratings from the expert analysts and the discomfort rating from the farmers. This test is designed to accommodate unequal sample sizes and, therefore, unequal variances.

Results (Table 4) revealed significant differences in ratings between analysts and farmers for the forearm, hand, and lower back. Farmers generally rated discomfort in these body parts as less in magnitude than analysts rated risk of injury for the same parts, based on the screening method.

We also examined whether experience played a mediating role in farmers' perceptions of pain and if this led to deviations from analyst ratings of injury risk. In specific, we made comparison of perceptions of pain for less and more experienced farmers with analyst ratings from the job screening. Groups of the four most experienced farmers (mean $=26.35$ years, SD $=11.09$ ) and four least experienced farmers (mean $=$ $3.75, \mathrm{SD}=1.5$ years) were selected to compare their discomfort ratings with analyst injury risk ratings.

Studentized t-tests were used for these analyses. For the most experienced farmers, results revealed significant differences in pain ratings from analysts' risk ratings for the forearm, hand, and leg (Table 5). Experienced farmers rated forearm and hand discomfort as less than analysts' risk ratings for the same body parts. However, the farmers' perceived discomfort in the leg was greater than the expert analysts' risk ratings.

For the least experienced group of farmers (Table 6), results indicated significant differences in pain ratings from analysts' ratings of risk of injury for the neck and lower back. In general, farmers with less experience in field plowing rated body part discomfort much lower in magnitude than ratings of risk of injury by expert analysts, based on the screening method. 
Table 5

Student's t-test results on rating scores between analysts and most experienced farmers for each body part

\begin{tabular}{lll}
\hline Body parts & \multicolumn{2}{c}{ Rating scores } \\
\hline Neck & $\mathrm{t}(6)=0.171$ & $p=0.8698$ \\
Shoulder & $\mathrm{t}(6)=-1.963$ & $p=0.0973$ \\
Forearm & $\mathrm{t}(6)=3.636$ & $p=\mathbf{0 . 0 1 0 9}^{*}$ \\
Hand & $\mathrm{t}(6)=4.947$ & $p=\mathbf{0 . 0 0 2 6}^{*}$ \\
Lower back & $\mathrm{t}(6)=1.024$ & $p=0.3453$ \\
Leg & $\mathrm{t}(6)=-5.502$ & $p=\mathbf{0 . 0 0 1 5}^{*}$ \\
\hline
\end{tabular}

Note: $*$ - significant at alpha $=0.05$ level.

Table 6

Student's t-test results on rating scores between analysts and least experienced farmers for each body part

\begin{tabular}{lll}
\hline Body parts & \multicolumn{2}{c}{ Rating scores } \\
\hline Neck & $\mathrm{t}(6)=15.982$ & $p<\mathbf{0 . 0 0 0 1}^{*}$ \\
Shoulder & $\mathrm{t}(6)=2.256$ & $p=0.0649$ \\
Forearm & $\mathrm{t}(6)=1.580$ & $p=0.1652$ \\
Hand & $\mathrm{t}(6)=2.166$ & $p=0.0734$ \\
Lower back & $\mathrm{t}(6)=50.752$ & $p<\mathbf{0 . 0 0 0 1}^{*}$ \\
Leg & $\mathrm{t}(6)=0.611$ & $p=0.5637$ \\
\hline
\end{tabular}

Note: $*$ - significant at alpha $=0.05$ level.

\subsection{Interview results}

Regarding working duration before the onset of pain, more experienced farmers reported feeling pain after working for 30-60 minutes, while less experienced farmers said they felt pain after 3-4 hours of work. Most participants indicated that they would take immediate rest for up to 30 minutes for "sharp pain", such as shoulder aches and cramps in the calves and/or toes. The farmers also reported self-massage during their intermittent rest periods. For other dull pains, farmers reported continuing work until completing the current task. A minority reported taking pain relief medicine after work. Related to this, the cost of muscle pain relievers (e.g., ibuprofen, acetaminophen) in Thailand (approximately $180 \mathrm{ThB}$ for 10 pills) is a substantial cost relative to a farmer's daily income (approximately 250-300 ThB per plowed plot).

With respect to the locations of body discomfort, farmers reported leg and foot pain occurred primarily when they were harrowing and leveling muddy soil. Farmers said they experienced pain while their feet were immersed in mud in a furrow. No pain was present, however, when the farmers walked over level ground.

Related to this, farmers reported experiencing cramping in the calf and toes during the point in the movement cycle at which they pushed their feet off the ground. They also reported pain near the lateral malleolus (end of the fibula at the ankle) and in the foot
Table 7

Significant correlations among the demographic variables and pain ratings

\begin{tabular}{llll}
\hline Variable & By variable & \multicolumn{2}{c}{ Correlation } \\
\hline Experience & Age & $r=0.7575$ & $p=0.0043$ \\
BMI & Weight & $r=0.7538$ & $p=0.0046$ \\
BMI & Age & $r=0.5883$ & $p=0.0441$ \\
Shoulder pain & Neck pain & $r=0.6304$ & $p=0.0280$ \\
Lower back pain & Neck pain & $r=0.7618$ & $p=0.0040$ \\
Lower back pain & Shoulder pain & $r=0.6228$ & $p=0.0305$ \\
Foot pain & Leg pain & $r=0.9984$ & $p=<0.0001$ \\
Leg pain & Experience & $r=0.5983$ & $p=0.0399$ \\
Foot pain & Experience & $r=0.5893$ & $p=0.0438$ \\
\hline
\end{tabular}

while bearing weight directly over the foot. However, the farmers indicated that minor pain in other body parts generally occurred when they were performing initial plowing on dry soil. These pains were experienced regardless of any specific point in the movement cycle and may be attributable to muscle stiffness at the beginning of a work cycle without proper stretching, etc.

\subsection{Correlational analyses of farmer demographics, pain ratings and cramping}

Based on the results of the discomfort survey and interviews, we conducted correlational analyses on farmer demographics with the occurrence of pain, as well as regression analyses to assess the utility of demographics for predicting leg and/or foot cramping. As shown in Table 2, the demographic variables we observed included age, height, weight, BMI, and experience. Correlations among these variables and pain ratings for the neck, shoulder, forearm and hand, lower back, leg, and foot were analyzed using Pearson product-moment coefficients. Here, it is important to note that pain in the forearm and hand was assigned a single rating by farmers; however, pain in the leg and foot was rated separately.

Table 7 presents correlations among the farmer demographic variables and pain ratings. (Pearson correlation coefficients with $\mathrm{p}$-values $<0.05$ were considered to be significant). Results revealed significant positive linear associations between farmer experience level and leg pain $(r=0.5983 ; p=0.0399)$ and foot pain $(r=0.5893 ; p=0.0438)$. Related to this, it was also found that farmer BMI significantly increased with years on the job (experience; $r=0.5885, p=$ 0.0441). All other significant correlations were among the demographic variables or were inter-correlations among pain ratings.

The second statistical analysis involved logistic regression modeling of the binary response ("yes" or 
"no") to the interview question regarding leg and/or foot cramping in terms of farmer demographic variables. There was a marginally significant positive relation of cramping with age $\left(\chi^{2}=2.8114, p=\right.$ $0.0936)$ and BMI $\left(\chi^{2}=3.7022, p=0.0543\right)$. Beyond this, farmer experience was highly significant $\left(\chi^{2}=\right.$ 5.7926, $p=0.0161$ ) in predicting leg and foot cramps. Farmers with a greater number of years in the field experienced more leg and foot cramps.

\section{Discussion}

Contrary to our hypothesis (H1), there were significant differences between the results of the ergonomicsrelated risk ratings from the job screening and farmer subjective ratings of forearm, hand and lower back pain. Analysts observed that farmers were exposed to highly repetitive motion and extreme postures at the forearm, hand and back posing high risk of injury. However, according to the expert analyst ratings, only moderate forces were applied to these body parts. It is possible that farmers primarily recall pain experiences based on how much force they had to apply to any object with a particular body part versus recalling the repetitiveness of their motions or extreme postures.

Based on the separate analyses of pain ratings from less and more experienced farmer, less experienced farmers' perceived pain in the upper and lower extremities was comparable in magnitude to the expert ratings of risk of injury for the same body parts. However, these farmers also experienced significantly less discomfort in the neck and lower back relative to analysts' risk ratings. These results might be attributable to neck and back pain being cumulative in nature as compared with muscle pain occurring in the arms and legs. The interview results also indicated that farmers with limited field experience may only perceive pain in the upper and lower limbs associated with specific activities, including initial field plowing on dry soil.

In contrast, for more experienced farmers, discomfort ratings for the lower extremity were substantially greater in magnitude than expert ratings of risk of injury for the leg. Based on the interviews, farmers specifically reported leg and feet pains that resulted from muscle cramping during foot push-off from the ground while working in muddy soil. When walking in wet and muddy ground, farmers reported difficulty in stabilizing their bodies. They also reported forceful and extensive toe movement to walk forward in the mud. High exertion of leg and foot muscles may lead to quick onset of fatigue and eventually muscle cramps due to lactic acid accumulation. As previously noted, it was not possible for the analysts in the job screening study to observe farmers' calves and feet in muddy soil during the harrowing and leveling stages of the field preparation process. This was a major disadvantage of that investigation and no ratings of risk of injury for the calves and feet were available for comparison with farmer pain ratings.

With respect to upper extremity pain (forearm and hand) reported by the most experienced farmers, ratings were significantly less in magnitude than the corresponding analysts' ratings of risk of injury. As compared with the least experienced farmers, these results were in agreement with H2.1. It is possible that the expert farmers had become more tolerant of pain in the upper extremity than their junior counterparts. Parakkat et al. [29] observed that more experienced farmers perceived higher subjective discomfort thresholds, as they generally reported lower levels of discomfort regardless of work conditions. Direct observations of farmers' work in the screening study and farmers' comments during the interviews also revealed development of smoother motion of the arms and hands (absent of jerk). Such movement patterns have been reported to be more efficient and safer [31,32]; thereby, reducing the occurrence of pain [16-18].

The correlation analyses on farmer demographics and pain ratings suggested that BMI increases with increases in rice farmer age. This was counter to the prior sport science literature [21]. Counter to our expectation $(\mathrm{H} 2.2)$ age was not significantly positively correlated with farmer pain ratings. However, age was marginally positively correlated with the occurrence of cramping in the legs and feet. It is possible that greater body mass with age produced greater loading on muscles and joints leading to cramping. Opposite to our expectation, increased farmer field experience was positively correlated with pain and cramping in the legs and feet. However, we also found that years on the job (experience) and age were highly correlated among the present farmer population. Further investigation is needed to pinpoint the exact underlying causes of perceived pain. Counter to expectation (H2.3), the measures of farmer height and weight were not significantly predictive of leg and foot cramping. That is, smaller farmers did not generally produce lower pain ratings for the field preparation task. 


\section{Conclusion}

This study investigated pain characteristics of rice farmers in the northeastern region of Thailand using self-ratings and structured interviews conducted by physical therapists regarding all stages of rice field preparation. The results of the investigation were compared with those of a job screening for ergonomicsrelated risk factors by expert analysts with a focus on the initial stage of plowing.

Results revealed that the neck, forearm, hand, and lower back were critical areas of body exposure to ergonomics-related risk (high motion repetition, force and extreme postures) of which farmers may be unaware. This finding was particularly relevant for less experienced farmers, who showed less concern for discomfort in the neck and lower back; while more experienced farmers expressed less pain in the forearms and hands. In cases where analysts' risk of injury assessments deviate from farmers' pain ratings, the pain ratings may represent the more appropriate outcome measure as a basis for reactive intervention design from the farmer perspective. Aside from these deviations among farmer pain assessments and expert analyst injury risk ratings, there was a general correspondence of the magnitude of results among the two studies for other body parts. The majority of the data from the present study served to further validate the results of the earlier job screening and the use of the approach with expert ergonomists for hazard identification and control. Therefore, the analyst ratings might be a more appropriate outcome to use a basis for proactive control measures to counter the development of pain.

Related to these findings, additional research should be conducted to identify effective arm and hand movement strategies of highly experienced farmers. The efficiency and effectiveness of movement patterns can be objectively examined by using muscle activity responses. Such strategies should be compared with the arm and hand movements of novice and less experienced farmers to develop effective approaches for instruction and training in appropriate work methods. Methods should prevent awkward work postures to minimize the risk of injury, especially for long-term neck and back pain or disability.

Results from this study also revealed leg and feet pain and cramps are a major issue when farmers work with barefeet in muddy fields. However, this did not appear to be a concern for the initial field plowing stage. In contrast, analyst ratings of risk of injury for the upper extremities in the initial plowing work were comparable to, or exceeded, farmer perceptions of pain for the overall field preparation process. This indicates that farmer perceived pain in the upper-extremity may be less of an issue in the later stages of harrowing and leveling.

Further research needs to assess farmers' body pain after each stage of the field preparation process with the objective of identifying specific activities that contribute to discomfort in the neck, back and upper and lower extremities. Such research should also identify common pain characteristics among stages of the process to specify common ergonomics interventions for controlling farmer exposure to risk factors and to reduce the occurrence of MSDs. Specification of interventions can be challenging, however, due to established farmer work practices and preferences. For example, walking with barefeet on a slippery surface can cause a sprain or impact injury due to a fall. Farmers do not prefer to wear boots, however, since boots easily get stuck in the mud. Ergonomists need to investigate novel foot protection for rice farmers that stabilizes the foot as well as facilitates forward walking.

From the correlational analyses of this study, it is clear that rice farmers' physical characteristics play a role in perceptions of body part pain and the occurrence of cramping. Unfortunately, the degenerative effects of aging and increases in BMI during a farmer's career are predictive of leg and feet problems. Furthermore, the number of years a farmer has spent in the field, and possible "wear and tear" on the body, was strongly correlated with the occurrence of cramping.

Further research needs to be conducted to pinpoint the exact underlying causes of farmer leg and foot cramping. Foot movement behavior and physical exams should be conducted to identify any forms of adaptation that have occurred with time leading the MSDs. Additional ergonomic interventions should be designed to address these adaptations specifically and should be tested for their ability to prevent MSDs. This type of research should be conducted with a larger sample of working farmers than used in the present study to promote the generalization of findings. Such research may ultimately promote the working health of rice farmers in Thailand and assist the country in safely achieving planned production goals for the export of Jasmine rice throughout the world.

\section{Acknowledgements}

This study was supported by grants from the Back Neck and Other Joint Pain Research Group, Khon 
Kaen University. David Kaber's work on this research report was supported by a grant from the U.S. National Institute for Occupational Safety and Health (NIOSH: No. 2 T42 OH008673-06). The opinions expressed in this report are those of the authors and do not necessarily reflect the views of NIOSH. We also thank Chatchai Phimphasak, Ploypailin Namkorn and Krittaya Saenlee for administrating the body part discomfort questionnaire and interviewing farmers.

\section{References}

[1] Chataigner J. Simultaneous growth and diversification of rice consumption in Europe and the USA. Proceedings of the Prospects for Rice Consumption in Europe Symposium. Verona, Italy; 1992.

[2] USDA. Rice Situation and Outlook Year Book. Washington, DC; 2001.

[3] Suwansri S, Meullenet J-F, Hankins JA, Griffin K. Preference Mapping of Domestic/Imported Jasmine Rice for U.S.-Asian Consumers. Journal of Food Science. 2002;67(6):2420-31.

[4] Office of Agricultural Economics. Agricultural Statistics [Internet]. [cited 2011 Nov 21]. Available from: http://www.oae. go.th/oae_report/stat_agri/main.php?lang=en.

[5] Kasikorn Research Center. K-Econ Analysis [Internet]. [cited 2011 Nov 21]. Available from: http://www.kasikornresearch. com/EN/K-EconAnalysis/Pages/Search.aspx?cid=4.

[6] Kirkhorn SR, Earle-Richardson G, Banks RJ. Ergonomic Risks and Musculoskeletal Disorders in Production Agriculture: Recommendations for Effective Research to Practice. Journal of Agromedicine. 2010;15(3):281-99.

[7] Fathallah FA. Musculoskeletal disorders in labor-intensive agriculture. Appl Ergon. 2010;41(6):738-43.

[8] Kar SK, Dhara PC. An evaluation of musculoskeletal disorder and socioeconomic status of farmers in West Bangal, India. Nepal Medical College Journal. 2007;9(4):245-9.

[9] Mamansari DU, Salokhe VM. The need for ergonomics considerations for the design and development of agricultural machinery in Thailand. J Hum Ergol (Tokyo). 1995;24(1):61-72.

[10] Baron S, Estill C, Steege A, Lalich N. Simple solutions: ergonomics for farm workers. National Institute for Occupational Safety and Health; 2001 page 1-53. Report No.: 2001111.

[11] Walker-Bone K, Palmer KT. Musculoskeletal Disorders in Farmers and Farm Workers. Occup Med (Lond). 2002;52(8): $441-50$.

[12] Swangnetr M, Namkorn P, Phimphasak C, Saenlee K, Kaber $\mathrm{D}$, Buranruk O, et al. Ergonomic analysis of rice field plowing. The 4th International Conference on Applied Human Factors and Ergonomics. San Francisco, CA; 2012.

[13] Armstrong T. The ACGIH TLV for hand activity level. In: Marras WS, Karwowski W, editors. Fundamentals and Assessment Tools for Occupational Ergonomics. Boca Raton (FL): CRC Press; 2006. page 41:1-14.

[14] McAtamney L, Nigel Corlett E. RULA: a survey method for the investigation of work-related upper limb disorders. Applied Ergonomics. 1993;24(2):91-9.

[15] Mishra W, Amitabha D, Iqbal R, Gangopadhyay S, Chandra AM. An integrative approach for evaluating work related musculoskeletal disorders. Work: A Journal of Prevention, Assessment and Rehabilitation. 2012;43(4):437-46.
[16] Gagnon M, Plamondon A, Gravel D, Lortie M. Knee movement strategies differentiate expert from novice workers in asymmetrical manual material handling. Journal of Biomechanics. 1996;29(11):1445-53.

[17] Plamondon A, Denis D, Delisle A, Larivière C, Salazar E. Biomechanical differences between expert and novice workers in a manual material handling task. Ergonomics. 2010; 53(10):1239-53.

[18] Chen Y-L, Lee Y-C, Chen C-J. Differences in lifting strength profiles between experienced workers and novices at various exertion heights. International Journal of Industrial Ergonomics. 2011;41(1):53-8.

[19] Maïsetti O, Boyas S, Guével A. Specific Neuromuscular Responses of High Skilled Laser Sailors during a Multi-Joint Posture Sustained Until Exhaustion. International Journal of Sports Medicine. 2006;27(12):968-75.

[20] Boyas S, Maïsetti O, Guével A. Changes in sEMG parameters among trunk and thigh muscles during a fatiguing bilateral isometric multi-joint task in trained and untrained subjects. Journal of Electromyography and Kinesiology. 2009;19(2):259-68.

[21] Watts PB, Martin DT, Durtschi S. Anthropometric profiles of elite male and female competitive sport rock climbers. Journal of Sports Sciences. 1993;11(2):113-7.

[22] Galganski ME, Fuglevand AJ, Enoka RM. Reduced Control of Motor Output in a Human Hand Muscle of Elderly Subjects During Submaximal Contractions. J Neurophysiol. 1993;69(6):2108-15.

[23] Laidlaw DH, Bilodeau M, Enoka RM. Steadiness is reduced and motor unit discharge is more variable in old adults. Muscle \& Nerve. 2000;23(4):600-12.

[24] Kuorinka I, Jonsson B, Kilbom A, Vinterberg H, BieringSørensen F, Andersson G, et al. Standardised Nordic questionnaires for the analysis of musculoskeletal symptoms. Applied Ergonomics. 1987;18(3):233-7.

[25] Saetan O, Khiewyoo J, Jones C, Ayuwat D. Musculoskeletal Disorders among Northeastern Construction Workers with Temporary Migration. Srinagarind Medical Journal. 2007; 22(2):165-73.

[26] Gangakhedkar SB, Kaber DB, Mosaly PR. Effects of scaffolding equipment interventions on muscle activation and task performance. Proceedings of the Human Factors and Ergonomics Society Annual Meeting. Santa Monica, CA; 2011. p. $975-9$.

[27] Rogers M, Gangakhedkar S, Kaber DB. Ergonomic evaluation of emergency veterinary clinic operations. Proceedings of the 2011 Applied Ergonomics Conference. Orlando, FL: IIE; 2011.

[28] Baron S, Hales T, Hurrell J. Evaluation of symptom surveys for occupational musculoskeletal disorders. Am. J. Ind. Med. 1996;29(6):609-17.

[29] Parakkat J, Yang G, Chany A-M, Burr D, Marras WS. The influence of lift frequency, lift duration and work experience on discomfort reporting. Ergonomics. 2007;50(3):396-409.

[30] Tayyari F, Smith JL. Occupational Ergonomics: Principles and Applications. London: Chapman \& Hall; 1997.

[31] Flash T, Hogan N. The coordination of arm movements: an experimentally confirmed mathematical model. J. Neurosci. 1985;5(7):1688-703.

[32] Hsiang SM, McGorry RW. Three different lifting strategies for controlling the motion patterns of the external load. Ergonomics. 1997;40(9):928-39. 